\title{
Effect of an older sibling and birth interval on the risk of childhood injury
}

\author{
Avery B Nathens, Margaret J Neff, Christopher H Goss, Ronald V Maier, \\ Frederick P Rivara
}

\begin{abstract}
Objective-Certain family structures have been identified as putting children at high risk for injury. To further define children at highest risk, we set out to explore the effect of an older sibling and birth interval on the risk of injury related hospital admission or death.

Methods-Data were analyzed using a case-control design. Cases and controls were identified by linking longitudinal birth data from Washington state (198996) to death certificate records and hospital discharge data obtained from the Washington State Comprehensive Hospital Abstract Reporting System and frequency matched in a 1:2 ratio on year of birth. Cases consisted of singleton children 6 years of age or younger who were hospitalized or died as a result of injury during the years 1989-96. Multivariate logistic regression was used to identify and adjust for confounding variables.
\end{abstract}

Results-There were 3145 cases and 8371 controls. The adjusted odds ratio for injury in children with an older sibling was 1.50 (95\% confidence interval 1.37 to 1.65). The effect was greatest in children under 2 years of age, and in those with a birth interval of less than two years. As the number of older siblings increased, so did the risk of injury, with the highest risk in children with three or more older siblings. Conclusion-These data suggest that the presence of an older sibling is associated with an increased risk of injury. The risk is highest in those with very short birth intervals. Potential mechanisms for this increased risk may relate to inadequate parental supervision. Pediatricians and other care providers need to be alert to these identifiable risk factors and then direct preventive strategies, such as home visits and educational programs, toward these families.

(Injury Prevention 2000;6:219-222)

Keywords: sibling; birth interval; family

Pulmonary/Critica

Care Medicine,

Harborview Medical

Center, Seattle,

Washington

M J Neff

C H Goss

Correspondence to:

Dr Avery B Nathens,

Harborview Medical Center,

Box 359796, 325 9th Ave,

Seattle, WA 98104, USA

(email:

anathens@u.washington.edu) $17 \%$ of all hospitalizations were injury related. ${ }^{12}$ Injury represents a major health issue for children and one for which it is critical to identify opportunities for intervention and prevention.

There have been several recent reports suggesting a relationship between certain family structures and perinatal or childhood morbidity and mortality, ${ }^{3}$ a phenomenon which is drawing significant attention in the lay press. ${ }^{4}$ Several of these studies have focused on the importance of family size, specifically maternal parity, on the risk of childhood injury. ${ }^{5}{ }^{6}$ These studies have consistently demonstrated an increased risk of injury in children born to families of large size. Although several hypotheses have been proposed to explain this relationship, including increased family stress, inadequate parental supervision, and household crowding, ${ }^{7-9}$ the causal pathway remains unclear. Clarification of these risk factors and the mechanisms involved would allow health care providers to identify those children who are at particularly high risk for injury.

To further explore the relationship between family size and childhood injury and to attain a greater understanding of the causal mechanisms involved, we set out to evaluate the association between the presence of an older sibling and the risk of childhood injury and the effect of birth interval on this relationship.

\section{Methods}

\section{DATA COLLECTION}

Data were analyzed using a case-control design. Study subjects were identified by linking longitudinal birth data from Washington state to death certificate and hospital discharge data obtained from the Washington State Comprehensive Hospital Abstract Reporting System. Cases consisted of singleton children 6 years of age or younger who were hospitalized or died as a result of injury during the years 1989-96, identified using International Classification of Disease, ninth revision external causes of injury codes E800-E999. Code groupings were accomplished as follows: unintentional injuries (E800-E869, E880E929), intentional injuries (E960-E969), and other injuries (E950-E959, E980-E989). Injuries due to surgical or medical procedures or misadventures (E870-E879), adverse effects of medicine and biologics in therapeutic use (E930-E949), legal intervention (E970E979), and operations of war (E990-E999) were excluded after initial case selection. As the focus was on unintentional injuries, where there is the greatest chance of benefit from risk identification and injury prevention interventions, analyses were limited to cases resulting 
Table 1 Risk factors for childhood injury

\begin{tabular}{|c|c|c|c|}
\hline Injury risk factor & $\begin{array}{l}\text { No (\%) with no injury } \\
(n=8371)\end{array}$ & $\begin{array}{l}\text { No (\%) with injury } \\
(n=3145)\end{array}$ & $\begin{array}{l}\text { Crude odds ratio } \\
(95 \% \text { CI })\end{array}$ \\
\hline \multicolumn{4}{|l|}{ Sibling status } \\
\hline No older sibling & $3517(42)$ & $1072(34)$ & 1 \\
\hline Older sibling & $4854(58)$ & $2073(66)$ & $1.40(1.29$ to 1.53$)$ \\
\hline \multicolumn{4}{|l|}{ Gender } \\
\hline Male & $4255(51)$ & $1882(60)$ & $1.44(1.33$ to 1.57$)$ \\
\hline Female & $4116(49)$ & $1263(40)$ & 1 \\
\hline \multicolumn{4}{|l|}{ Race } \\
\hline White & $6236(75)$ & $2345(75)$ & 1 \\
\hline Black & $401(4.8)$ & $154(4.9)$ & $1.02(0.84$ to 1.24$)$ \\
\hline Hispanic & $797(9.5)$ & $275(8.7)$ & $0.92(0.79$ to 1.06$)$ \\
\hline Asian & $426(5.1)$ & $146(4.6)$ & $0.91(0.75$ to 1.11$)$ \\
\hline Other/unknown & $511(6.1)$ & $225(7.2)$ & $1.17(0.99$ to 1.38$)$ \\
\hline \multicolumn{4}{|l|}{ Maternal age } \\
\hline$\leqslant 14$ & $25(0.31)$ & $17(0.54)$ & $1.88(1.01$ to 3.49$)$ \\
\hline $15-19$ & $861(10)$ & $369(12)$ & $1.18(1.02$ to 1.36$)$ \\
\hline $20-24$ & $2130(25)$ & $762(24)$ & $0.99(0.88$ to 1.10$)$ \\
\hline $25-29$ & $2538(30)$ & $920(29)$ & 1 \\
\hline$\geqslant 30$ & $2817(34)$ & $1077(34)$ & $1.05(0.95$ to 1.17$)$ \\
\hline \multicolumn{4}{|l|}{ Marital status } \\
\hline Married & $6244(75)$ & $2298(73)$ & 1.0 \\
\hline Single & $2096(25)$ & $841(27)$ & $1.09(0.99$ to 1.20$)$ \\
\hline Unknown & $31(0.38)$ & $6(0.19)$ & $0.53(0.22$ to 1.26$)$ \\
\hline \multicolumn{4}{|l|}{ Maternal education $\star$} \\
\hline Less than high school & $563(18)$ & $240(22)$ & $1.48(1.22$ to 1.79$)$ \\
\hline High school & $968(30)$ & $349(32)$ & $1.25(1.06$ to 1.48$)$ \\
\hline College & $1329(42)$ & $383(35)$ & 1 \\
\hline Unknown & $323(10)$ & $122(11)$ & $1.31(1.03$ to 1.66$)$ \\
\hline \multicolumn{4}{|l|}{ Gestational age } \\
\hline Term & $6261(75)$ & $2242(71)$ & 1 \\
\hline Preterm (<37 weeks) & $420(5)$ & $175(6)$ & $1.16(0.97$ to 1.40$)$ \\
\hline Unknown & $1690(20)$ & $728(23)$ & $1.20(1.09$ to 1.33$)$ \\
\hline \multicolumn{4}{|l|}{ Birth weight (g) } \\
\hline$\geqslant 2500$ & $7952(95)$ & $2994(95)$ & 1 \\
\hline$<2500$ & $408(4.9)$ & $147(4.7)$ & $0.96(0.79$ to 1.16$)$ \\
\hline Unknown & $11(0.15)$ & $4(0.13)$ & $0.97(0.31$ to 3.04$)$ \\
\hline \multicolumn{4}{|l|}{ First prenatal visit } \\
\hline First trimester & $6356(76)$ & $2344(75)$ & 1 \\
\hline Beyond first trimester & $1635(20)$ & $631(20)$ & $1.05(0.94$ to 1.16$)$ \\
\hline No prenatal care & $370(4.4)$ & $169(5.4)$ & $1.24(1.03$ to 1.49$)$ \\
\hline Unknown & $10(0.12)$ & $1(0.03)$ & $0.27(0.03$ to 2.12$)$ \\
\hline \multicolumn{4}{|l|}{ Insurance status } \\
\hline Insured & $5289(63)$ & $1901(60)$ & 1 \\
\hline Uninsured & $2962(35)$ & 1212 (39) & $1.14(1.05$ to 1.24$)$ \\
\hline Unknown & $120(1.4)$ & $32(1.0)$ & $0.74(0.50$ to 1.10$)$ \\
\hline
\end{tabular}

^Data only available from 1992-96; based on 3183 controls and 1094 cases.

from unintentional injuries. Controls were randomly selected products of singleton births who did not have an injury related hospitalization or death in the state of Washington over this same time interval. Controls were frequency matched to cases in a 2:1 ratio by year of birth. After excluding the cases with $\mathrm{E}$ codes as described above, final matching of controls to cases was slightly greater than $2: 1$.

The presence of an older sibling was determined from longitudinal birth record data and was defined as having an older sibling born in the state of Washington and alive at the time of the index subject's birth. Birth interval, the time between the index subject's birth and the next older sibling, was considered to be the time (in years) between the birth of the index case and the previous live birth. Several risk factors for injury were identified from birth certificate information including maternal factors (age, education, trimester of first prenatal visit, marital status, maternal race, and insur-

Table 2 The effect of an older sibling on the risk of injury, by age at time of injury

\begin{tabular}{llll}
\hline Age (years) & $\begin{array}{l}\text { No (\%) with no older } \\
\text { sibling }\end{array}$ & $\begin{array}{l}\text { No (\%) with older } \\
\text { sibling }\end{array}$ & $\begin{array}{l}\text { Adjusted odds ratio * } \\
\text { (95\% CI) }\end{array}$ \\
\hline All $(\mathrm{n}=3145)$ & $1072(34)$ & $2073(66)$ & $1.50(1.37$ to 1.65$)$ \\
$0-2(\mathrm{n}=2411)$ & $816(34)$ & $1595(66)$ & $1.56(1.41$ to 1.73$)$ \\
$3-4(\mathrm{n}=556)$ & $194(35)$ & $362(65)$ & $1.35(1.11$ to 1.63$)$ \\
$>4(\mathrm{n}=178)$ & $62(35)$ & $116(65)$ & $1.28(0.92$ to 1.78$)$ \\
\hline
\end{tabular}

^Adjusted for maternal age. ance status) and child factors (gender, birth weight, gestational age, year of birth). These injury risk factors were evaluated as potential confounding variables in the analysis. In addition, the effect of an older sibling on the risk of injury was assessed as a function of age at the time of injury, birth interval, and the number of older siblings.

STATISTICAL ANALYSIS

The effect of an older sibling on injury related hospitalization or death was assessed using logistic regression and Mantel-Haenszel stratified analysis. Results are presented as the odds ratio of injury associated with the presence of an older sibling. All injury related risk factors described above were evaluated as potential confounding variables using a change in estimates approach. A change in the point estimate of the odds ratio in excess of $10 \%$ was used to identify a risk factor as an important confounding variable, resulting in its inclusion in the regression model. ${ }^{10}$ Analyses were conducted using Stata software (Stata Statistical Software: release 6.0. College Station, TX: Stata Corporation, 1999).

\section{Results}

Through the years 1989-96, 4260 children 6 years of age and under were either admitted to a hospital or died as a result of injury in the state of Washington. These children were frequency matched on year of birth to 8514 controls; matching was accomplished in all but six cases. Of the cases, the following were excluded: 895 cases in which injuries occurred as a result of medical misadventures or adverse effects of medical care and 174 cases resulting from intentional or other injuries. Twin births were identified in 53 controls and 18 cases, while sibling status could not be evaluated in 90 controls and 28 cases. These subjects were excluded, leaving 8371 controls and 3145 cases for subsequent analysis.

Among the 3145 injured children, $66 \%$ had an older sibling. By contrast, only $58 \%$ of control subjects had an older sibling, resulting in a crude odds ratio of injury of $1.40 \quad(95 \%$ confidence interval (CI) 1.29 to 1.53 ) in those children with an older sibling (table 1). Several other maternal and child demographic variables were significantly associated with injury including maternal age $<20$ years, unwed mother, no maternal college education, absence of prenatal care, uninsured status, preterm birth, and male gender. Of these factors, only maternal age was noted to confound the effect of an older sibling on injury risk. The adjusted odds ratio for injury in children with an older sibling was 1.50 (95\% CI 1.37 to 1.65 ). The association was strongest in the youngest age stratum (age <2 years) (table 2).

To better understand the association between the presence of an older sibling and childhood injury, we evaluated two additional environmental factors we postulated may help explain the observed effect. First, we assessed whether the number of older siblings had any effect on the risk of injury. As is shown in table 
Table 3 The effect of an older sibling on the risk of injury, by number of older siblings

\begin{tabular}{llll}
\hline No of older siblings & $\begin{array}{l}\text { No (\%) with } \\
\text { no injury }\end{array}$ & $\begin{array}{l}\text { No (\%) with } \\
\text { injury }\end{array}$ & $\begin{array}{l}\text { Adjusted odds ratio * } \\
\text { (95\% CI) }\end{array}$ \\
\hline $\begin{array}{l}\text { None }(\mathrm{n}=4589) \\
1(\mathrm{n}=3785)\end{array}$ & $3517(77)$ & $1072(23)$ & 1.0 \\
$2(\mathrm{n}=1979)$ & $2709(72)$ & $1076(28)$ & $1.39(1.26$ to 1.54$) \dagger$ \\
$\geqslant 3(\mathrm{n}=1163)$ & $1359(69)$ & $620(31)$ & $1.63(1.44$ to 1.85$) \dagger$ \\
\hline
\end{tabular}

$\star$ Adjusted for maternal age.

$\mathrm{tp}<0.01$, score test for trend of odds.

Table 4 The effect of an older sibling on the risk of injury, by birth interval

\begin{tabular}{llll}
\hline Birth interval (years) & $\begin{array}{l}\text { No (\%) with } \\
\text { no injury }\end{array}$ & $\begin{array}{l}\text { No (\%) with } \\
\text { injury }\end{array}$ & $\begin{array}{l}\text { Adjusted odds ratio } \\
\text { (95\% CI) }\end{array}$ \\
\hline $\begin{array}{l}\text { No older sibling }(\mathrm{n}=4589) \\
<2(\mathrm{n}=1728)\end{array}$ & $3517(77)$ & $1072(23)$ & 1.0 \\
$2-4(\mathrm{n}=2621)$ & $1172(68)$ & $556(32)$ & $1.64(1.44$ to 1.85$)$ \\
$>4(\mathrm{n}=1779)$ & $1855(71)$ & $766(29)$ & $1.46(1.30$ to 1.64$)$ \\
Unknown $(\mathrm{n}=799)$ & $563(70)$ & $515(29)$ & $1.43(1.25$ to 1.64$)$ \\
\hline
\end{tabular}

^Adjusted for maternal age. the current study. Lacking in these aforementioned studies is the relationship between age at time of injury or birth interval and injury risk. These relationships may offer some insight into the mechanism by which an older sibling increases the risk of injury.

There are several possible explanations for these results. First, the presence of an older sibling may impair the ability of the parent(s) to adequately supervise the younger child. Alternatively, the younger child, with less developed motor skills and judgment, may attempt to keep up with the older sibling, leading to injury. Two lines of evidence suggest that the principal mechanism by which an older sibling increases the risk of injury is through lack of adequate supervision. Injury risk was greatest in children under 2 years of age and in those with short birth intervals. These younger children are least likely to attempt to keep up with their only slightly older siblings. Further, the presence of a short birth interval in a sibling cohort in whom the younger is less than 2 years of age may simply be a surrogate for having two young children at home, again stressing the supervisory capacities of the parent or guardian.

Although children with the shortest birth interval appear to be at highest risk, there is clearly an increased risk in children with longer birth intervals compared with those without any siblings. One possible mechanism for this effect may relate to the appointment of a supervisory role to an older sibling whose judgment and maturity may be inadequate for the task. In two separate studies evaluating the circumstances surrounding infant bathtub drownings, children were being supervised by an older sibling in greater than $30 \%$ of incidents. ${ }^{13}{ }^{14}$ In yet another study, an older sibling was supervising $11 \%$ of children with injuries who were brought to an emergency department at the time of the injury. ${ }^{15}$ In an additional study, older siblings were noted to exert a significant influence on younger siblings' judgment about high risk activities. ${ }^{16}$ Taken together, these data in concert with the findings in the current study, suggest that lack of adequate supervision may be the primary cause for the increased risk of injury in children with an older sibling.

There are two principal limitations in the interpretation of these data. Linked birth certificate and hospital discharge data, although informative, provide no information of the role or the presence of the birth sibling at the time of injury. In this regard, other confounding variables not adequately controlled for may explain the relationship of injury to an older sibling. Additionally, potential misclassification of those with and without an older sibling exists due to the potential for sibling death or the presence of adoptive siblings or siblings born outside the state of Washington; however, there is no reason to suspect that such misclassification would be systematic.

\section{Implications for prevention}

Injury prevention strategies involve first identifying those at high risk for injury. In concord- of Tennessee from 1985 to $1994 .^{6}$ These reports are supportive of the data presented in 
ance with previous studies, we demonstrated that higher parity was associated with an increased risk of injury. However, the findings in the current study also provide additional information regarding the sociodemographic profile of children at high risk for injury. Children under 2 years of age with a sibling less than two years older are those at highest risk. We speculate, but cannot prove, that the principal reason for this increased risk may be inadequate supervision. These risk factors are readily identifiable to physicians and other caregivers. Physicians and other caregivers should target these high risk families for injury prevention strategies. For example, through their effect on increasing the social support network of mothers, home visiting programs have been reported to significantly decrease the risk of injury to children under 2 years of age. ${ }^{17}$ Such approaches should be more widely implemented.

1 National Center for Injury Prevention and Control. Childhood injury fact sheet-unintentional injury (web childhood injury fact sheet-unintentional injury (web

2 Schappert SM. National ambulatory medical care survey: 1994 summary. Advance Data 1996;273:1-18.

3 Zhu BP, Rolfs RT, Nangle BE, et al Effect of the interval between pregnancies on perinatal outcomes. $N$ Engl $\mathcal{F} \mathrm{Med}$ 1999;340:589-94
4 Springen K. Spaced-out siblings. Newsweek 5-17-1999.

5 Brenner RA, Overpeck MD, Trumble AC, et al. Deaths attributable to injuries in infants, United States, 19831991. Pediatrics 1999;103(5 pt 1):968-74.

6 Scholer SJ, Mitchel EF Jr, Ray WA. Predictors of injury mortality in early childhood. Pediatrics 1997;100(3 pt 1):342-7.

7 Pless IB, Peckham CS, Power C. Predicting traffic injuries in childhood: a cohort analysis. F Pediatr 1989;115:932-8.

8 Braddock M, Lapidus G, Gregorio D, et al. Population, income, and ecological correlates of child pedestrian injury. Pediatrics 1991;88:1242-7.

9 Christoffel KK, Donovan M, Schofer J, et al. Psychosocial factors in childhood pedestrian injury: a matched casecontrol study. Kid's'n'Cars Team. Pediatrics 1996;97:3342

10 Mickey RM, Greenland S. The impact of confounder selection criteria on effect estimation. Am f Epidemiol 1989;129: 125-37.

11 Cummings $\mathrm{P}$, Theis $\mathrm{MK}$, Mueller BA, et al. Infant injury death in Washington State, 1981 through 1990. Arch Pediatr Adolesc Med 1994;148:1021-6.

12 Scholer SJ, Hickson GB, Ray WA. Sociodemographic factors identify US infants at high risk of injury mortality. factors identify US infants at high

13 Jensen LR, Williams SD, Thurman DJ, et al. Submersion injuries in children younger than 5 years in urban Utah. West F Med 1992;157:641-4.

14 Rauchschwalbe R, Brenner RA, Smith GS. The role of bathtub seats and rings in infant drowning deaths. Pediatrics $1997 ; 100(4): e 1$

15 Rivara FP, Kamitsuka MD, Quan L. Injuries to children younger than 1 year of age. Pediatrics 1988;81:93-7.

16 Morrongiello BA, Bradley MD. Sibling power: influence of older siblings' persuasive appeals on younger siblings' judgements about risk taking behaviours. Inj Prev 1997;3: judger $23-8$.

17 Roberts I, Kramer MS, Suissa S. Does home visiting prevent childhood injury? A systematic review of randomised controlled trials. BMF 1996;312:29-33.

\section{New gun control measures in the US}

Following the massacre at a Colorado high school, President Bill Clinton called for sweeping moves to restrict the sale of guns and explosives. Predictably, opponents in Congress (who obviously do not subscribe to the evidence based school of thinking) challenged the idea that laws could remedy this (or any other) complex social problem. The cornerstones of Clinton's proposal were mandatory child safety locks; background checks of purchasers; a lifetime ban on gun ownership for those who commit violent crimes as juveniles, and a three day waiting period for all handgun purchases. Senate Republican leader Trent Lott referred to the plan as a "typical knee-jerk reaction".

Editors note: I refer to is as eminently sensible and long overdue.

\section{Personalized guns}

An editorial in the $B M Y$ by Stephen Teret and Daniel Webster argues that personalized guns could help reduce gun related deaths and that this goal can be achieved. They state that this is preferable to moves to ban handguns or to buy them back from their owners. In spite of reports in Injury Prevention (and elsewhere) demonstrating the importance of safe storage or the use of trigger locks as deterrents, Teret and Webster are convinced that "the most effective method for reducing tragedies cause by children with guns is to require that all firearms be personalised and childproof so that only an authorised user can operate a gun". (Personalizing is a process whereby guns can only be used after the gun is activated by an owner's fingerprint or by pressing buttons in a certain sequence.)

Editors note: There appears to be broad public support for this requirement and although the technology exists, some of us may still be wondering why the US is still so opposed to banning handguns. 